\title{
Evaluación de la Actividad Antibacteriana "in Vitro" del Extracto Alcohólico de las Hojas de Polylepis rugulosa ("queñua") Frente a Cultivos Bacterianos Uropatógenos Aislados en el Hospital Hipólito Unanue - Tacna
}

\author{
Evaluation of the Antibacterial "In Vitro" Activity of the Alcoholic \\ Extract of Polylepis rugulosa ("Queñua") Versus Bacterial \\ Uropathogenic Cultures Isolated in Hipólito Unanue Hospital - Tacna
}

\author{
César Julio Cáceda Quiroz
}

\begin{abstract}
RESUMEN:
Existen alrededor de 250,000 especies de plantas medicinales, de las cuales se tomó las hojas de Polylepis rugulosa ("queñua") para extraer su aceite esencial y enfrentarlo a cultivos bacterianos uropatógenos aislados en el Hospital Hipolito Unanue-Tacna. Los objetivos fueron: Realizar el estudio fitoquimico y determinar la actividad antibacteriana "in vitro" del extracto hidroalcohólico de las hojas de Polylepis rugulosa ("queñua") frente a Staphylococcus aureus ATCC 25923 y la cepa uropatógena Escherichia coli. La sensibilidad bacteriana mediante la Concentración Mínima Inhibitoria (MIC) del extracto hidroalcohólico de las hojas de Polylepis rugulosa ("queñua") frente a Staphylococcus aureus ATCC 25923 fue de $4,375 \mathrm{mg} / \mathrm{mL}$ y para Escherichia coli fue de $3,125 \mathrm{mg} / \mathrm{mL}$.
\end{abstract}

Palabras Clave: Polylepis rugulosa ("queñua"), marcha fitoquimica preliminar, actividad antibacteriana, Staphylococcus aureus y cepa uropatógena Escherichia coli

ABSTRAC:

There are about 250,000 species of medicinal plants, out of which leaves of Polylepis rugulosa ("queñua ") were taken to extract the essential oil and deal with them in uropathogenic bacterial cultures isolated in Hipolito Unanue Hospital Tacna. The objectives were: to carry out the phytochemical study and determine the antibacterial activity "in vitro" from the hydroalcoholic extract of the leaves Polylepis rugulosa ("queñua") versus Staphylococcus aureus ATCC 25923 and uropathogenic strain Escherichia coli. The bacterial sensitivity Bacterial Minimum Concentration (MIC) of the hydroalcoholic extract of the leaves of Polylepis rugulosa ("queñua") versus Staphylococcus aureus ATCC 25923 was $4,375 \mathrm{mg} / \mathrm{mL}$ and for Escherichia coliwas $3,125 \mathrm{mg} / \mathrm{mL}$.

Key words: Polylepis rugulosa ("queñua") application of phytochemical preliminary, antibacterial activity, Staphylococcus aureus and vine-stock uropatógena Escherichia coli. 


\section{INTRODUCCIÓN:}

Existen alrededor de 250,000 especies de plantas medicinales, de las cuales sólo conocemos aproximadamente el $10 \%$, referencia que indica lo mucho por investigar y el gran potencial sobre futuros medicamentos de fuentes naturales. El incremento de infecciones y resistencias causadas por bacterias conduce a buscar nuevos productos antibacterianos naturales.

\section{Objetivos}

$\Delta$

Determinar la actividad antibacteriana "in vitro" del extracto hidroalcohólico de las hojas de Polylepis rugulosa ("queñua") frente a Staphylococcus aureus ATCC 25923 y la cepa uropatógena Escherichia coli.

A Determinar la concentración del extracto hidroalcohólico de las hojas de Polylepis rugulosa ("queñua") en la actividad antibacteriana "in vitro" frente a Staphylococcus aureus ATCC 25923y la cepa uropatógena Escherichia coli.

\section{MATERIALES YMÉTODOS}

4 Material vegetal: Extracto hidroalcohólico de hojas de Polylepis rugulosa ("queñua")

4 Material biológico: Cepas de:

$>$ Sthaphylococcus aureus ATCC 25923

$>$ Escherichia coli uropatógena

\section{Recolección}

Se recolectaron hojas de Polylepis rugulosa ("queñua") durante su época de floración, entre los meses de febrero a mayo del 2011, de las faldas del sur y este del Volcán Yukamani, a una hora de la provincia Candarave, ubicada a 3,415msnm, del Departamento de Tacna. Las hojas recolectadas se encontraban en buen estado, no deterioradas, se envolvieron con papel kraft y se colocaron en cajas de cartón con su respectivo rótulo y se transportó hasta su procesamiento posterior.

\section{Desecación y Molienda:}

En el laboratorio las hojas de Polylepis rugulosa ("queñua") se limpiaron de impurezas, se secaron para su conservación y mantenimiento de los componentes del vegetal fresco y se mantuvieron a temperatura ambiente en un área fresca y seca, resguardada de la luz para no alterar los metabolitos secundarios presentes en las hojas de la especie en estudio.
Las hojas se trituraron mecánicamente en molino de bolas a $500 \mathrm{rpm}$ durante dos horas, y se guardaron para su conservación en frascos de boca ancha de color ámbar debidamente rotulado.

\section{PREPARACIÓN DEL EXTRACTO HIDROALCOHÓLICO}

\section{Obtención del extracto hidroalcohólico}

Para la obtención de los principios activos se empleó la técnica de maceración en agua y alcohol $70 \%$. En un envase estéril de vidrio color ámbar se colocó en su interior 20 gramos de hojas de Polylepis rugulosa ("queñua") secas previamente triturada. Luego se añadió $100 \mathrm{~mL}$ (agua y alcohol $70 \%$ ) hasta que cubrió por completo el contenido de las hojas, este frasco se agitó tres veces por día; después de 5 días de maceración se filtró a través de doble papel de filtro Wathman $\mathrm{N}^{\circ} 41$, posteriormente se procedió a la evaporación a sequedad en estufa a $37^{\circ} \mathrm{C}$ de temperatura, obteniéndose, de esta manera los principios activos y se comprobó la esterilidad del extracto mediante la siembra en agar Müeller-Hinton.

\section{Diluciones del extracto hidroalcohólico}

Se realizó por método de dilución; usando $250 \mathrm{mg}$ de extracto hidroalcohólico seco disuelto en $1 \mathrm{~mL}$ de agua bidestilada. Con la solución obtenida del extracto hidroalcohólico se prepararon 9 diluciones de ensayo cuyas concentraciones corresponden:

\begin{tabular}{|c|c|c|c|c|c|c|c|c|c|}
\hline$N^{\circ}$ & 1 & 2 & 3 & 4 & 5 & 6 & 7 & 8 & 9 \\
\hline$V(\mu l)$ & 5,0 & 7,5 & 10,0 & 12,5 & 15,0 & 17,5 & 20,0 & 22,5 & 25,0 \\
\hline $\begin{array}{c}\text { Conc. } \\
\text { (mg/mL) }\end{array}$ & 1,25 & 1,875 & 2,5 & 3,125 & 3,75 & 4,375 & 5,0 & 5,625 & 6,25 \\
\hline
\end{tabular}

Las pruebas experimentales con las hojas de Polylepis rugulosa ("queñua") permitió determinar la presencia de los constituyentes químicos a través del estudio fitoquímico preliminar y la actividad antibacteriana in vitro del extracto hidroalcohólico de las hojas de Polylepis rugulosa ("queñua"), utilizando el método de difusión del disco (Kirby Bauer) con 5 repeticiones a diferentes concentraciones, obteniéndose la Concentración Mínima Inhibitoria (CMI)y el método de dilución en medio líquido para obtener la Concentración Mínima Bactericida (CMB) del extracto hidroalcohólico de las hojas de "queñua". Se observó la sensibilidad antibacteriana tanto para Staphylococcus aureus ATCC 25923, así como para Escherichia coli. 


\section{RESULTADOS}

Tabla $\mathrm{N}^{\circ} 01$. Evaluación de la actividad antibacteriana "in vitro" del extracto hidroalcohólico de las hojas de Polylepis rugulosa ("queñua") frente a Staphylococcus aureus ATCC 25923 por el método de difusión del disco (Kirby Bauer).

\begin{tabular}{|c|c|c|c|c|c|c|c|c|}
\hline \multirow{4}{*}{ GRUPOS } & \multirow{4}{*}{ Trat. } & \multirow{4}{*}{$\begin{array}{l}\text { Conc. } \\
m g / m L\end{array}$} & \multicolumn{5}{|c|}{ Repeticiones } & \multirow{2}{*}{ PROMEDIO } \\
\hline & & & \multicolumn{5}{|c|}{ Staphylo coccus aure us ATC C 25923} & \\
\hline & & & \multicolumn{5}{|c|}{ halos de inhibición $(\mathrm{mm})$} & Prom. \\
\hline & & & 1 & II & III & $I V$ & $V$ & $m m$ \\
\hline \multirow{9}{*}{$\begin{array}{c}\text { Extracto } \\
\text { hidroalcohólico de } \\
\text { las hojas de } \\
\text { Polylepis } \\
\text { rugulosa("queñua") }\end{array}$} & $T 1$ & 1,25 & 6,5 & 5,95 & 6,3 & 6,1 & 6,4 & 6,25 \\
\hline & $T 2$ & 1,875 & 7,4 & 7,0 & 6,8 & 7,1 & 6,7 & 7,0 \\
\hline & $T 3$ & 2,5 & 8,5 & 8,75 & 8,6 & 8,1 & 8,3 & 8,45 \\
\hline & $T 4$ & 3,125 & 9,3 & 9,85 & 9,8 & 9,3 & 9,25 & 9,5 \\
\hline & $T 5$ & 3,75 & 9,9 & 10,25 & 10,05 & 10,3 & 10,5 & 10,2 \\
\hline & T6 & 4,375 & 10,95 & 11,45 & 11,25 & 11,3 & 11,05 & 11,2 \\
\hline & $T 7$ & 5,0 & 13,05 & 12,95 & 13 & 13,2 & 13,3 & 13,1 \\
\hline & $T 8$ & 5,625 & 13,3 & 13,45 & 13,25 & 13,5 & 13,75 & 13,45 \\
\hline & T9 & 6,25 & 15,6 & 15,45 & 15,4 & 15,5 & 15,3 & 15,45 \\
\hline \multirow{2}{*}{ Control } & \multicolumn{2}{|c|}{ Control - } & \multicolumn{5}{|c|}{ Sin extracto } & Control - \\
\hline & \multicolumn{2}{|c|}{ Control +} & \multicolumn{5}{|c|}{ A gar MüellerHinton } & Control + \\
\hline \multirow{3}{*}{$\begin{array}{l}\text { An tibiótico } \\
\text { (Discos)* }\end{array}$} & $T$ (Cip) & 5,0 & 21,5 & 21,4 & 22,6 & 22,7 & 21,8 & 22 \\
\hline & $T(G m)$ & 10 & 16,8 & 17,2 & 16,5 & 17,1 & 17,4 & 17 \\
\hline & $T(A z d)$ & 15 & 14,7 & 15,4 & 14,6 & 15,5 & 14,8 & 15 \\
\hline
\end{tabular}

Fuente: Elaboración propia.

En la Tabla $\mathrm{N}^{\circ} 01$ se expresa los promedios de los halos de inhibición a diferentes concentraciones del extracto hidroalcohólico ("queñua"), encontrándose que la concentración de $6,25 \mathrm{mg} / \mathrm{mL}$ generó el halo de mayor tamaño. Con respecto a los halos de inhibición producidos por los antibióticos comercializados en discos, se encontró que Ciprofloxacino (Cip) fue el que presentó el mayor diámetro de halo de inhibición (22 $\mathrm{mm}$ ); seguido por Gentamicina (Gm) con un halo de 17 mm y Azitromicina (Azd) con 15 mm de diámetro.

Tabla $\mathbf{N}^{\circ}$ 02. Evaluación de actividad antibacteriana "in vitro" del extracto hidroalcohólico de las hojas dePolylepis rugulosa ("queñua") frente ala cepa uropatógena Escherichia coli por método de difusión del disco (Kirby Bauer).

\begin{tabular}{|c|c|c|c|c|c|c|c|c|}
\hline \multirow{4}{*}{ Tratamiento } & \multirow{3}{*}{ Conc. } & \multirow{3}{*}{ Volumen } & \multicolumn{5}{|c|}{ Repeticiones } & \multirow{3}{*}{ Promedio } \\
\hline & & & \multicolumn{5}{|c|}{ cepa uropatógena de E. coli } & \\
\hline & & & \multicolumn{5}{|c|}{ halos de inhibición $(\mathrm{mm})$} & \\
\hline & $m \mathrm{~g} / \mathrm{mL}$ & $(u l)$ & 1 & II & III & IV & $\bar{V}$ & $P x(\mathrm{~mm})$ \\
\hline$T 1$ & 1,25 & 5,0 & 8,1 & 8,0 & 8,3 & 7,9 & 8,2 & 8,1 \\
\hline$T 2$ & 1,875 & 7.5 & 9,25 & 9,35 & 9,4 & 9,3 & 9,45 & 9,35 \\
\hline$T 3$ & 2,5 & 10 & 10,6 & 11,2 & 10,85 & 10,7 & 10,9 & 10,85 \\
\hline$T 4$ & 3,125 & 12.5 & 10,95 & 11,15 & 11,5 & 11,8 & 11,35 & 11,35 \\
\hline$T 5$ & 3,75 & 15 & 12,9 & 12,3 & 12,6 & 13,05 & 12,4 & 12,65 \\
\hline T6 & 4,375 & 17,5 & 12,5 & 13,4 & 13,15 & 12,8 & 12,9 & 12,95 \\
\hline$T 7$ & 5,0 & 20 & 13,4 & 13,9 & 13,8 & 13,2 & 13,45 & 13,55 \\
\hline$T 8$ & 5,625 & 22,5 & 14,95 & 14,5 & 14,45 & 14,9 & 15,2 & 14,8 \\
\hline$T 9$ & 6,25 & 25 & 15,7 & 15,5 & 15,6 & 15,3 & 15,4 & 15,5 \\
\hline Control - & Control - & $C-$ & \multicolumn{5}{|c|}{ Sin extracto } & Control - \\
\hline Control + & Control + & $C+$ & \multicolumn{5}{|c|}{ Agar Müeller Hinton } & Control + \\
\hline
\end{tabular}

Fuente: Elaboración propia.

En la Tabla $\mathrm{N}^{\circ} 02$, mediante el método de difusión del disco (Kirby Bauer), se evaluó la actividad antibacteriano del extracto hidroalcohólico de las hojas de "queñua"frente ala cepa $\boldsymbol{E}$. coli, reportándose que de los nueve tratamientos, la concentración $6,25 \mathrm{mg} / \mathrm{mL}$ fue la que generó mayor promedio de halo de inhibición
$(15,5 \mathrm{~mm})$ y los controles evidenciaron la validez de las variaciones de los promedios resultante por el extracto hidroalcohólico. El control negativo mostró crecimiento bacteriano en el medio de cultivo de la placa control y el control positivo manifiesta la ausencia de halos de inhibición. 
Tabla $\mathbf{N}^{\circ}$ 03: CMI y CMB producido por la actividad antibacteriana "in vitro" del extracto hidroalcohólico de las hojas de Polylepis rugulosa ("queñua") frente a Staphylococcus aureus ATCC 25923.

\begin{tabular}{|c|c|c|c|c|}
\hline$N^{*}$ PLACA & $\begin{array}{c}\text { Conc } \\
(\mathbf{m g} / \mathrm{mL})\end{array}$ & UFC/Placa & Turbidez & Observaciones \\
\hline 1 & 4,23 & 10 & $T$ & \\
\hline 2 & 4.3146 & 5 & $T$ & \\
\hline 3 & 4,375 & 3 & $N T$ & CMI \\
\hline 4 & 4.4838 & 0 & $N T$ & CMB \\
\hline 5 & 4,5684 & 0 & $N T$ & \\
\hline 6 & 4,653 & 0 & $N T$ & \\
\hline 7 & 4.7376 & 0 & $N T$ & \\
\hline 8 & 4,8222 & 0 & $N T$ & \\
\hline 9 & 4.9068 & 0 & $N T$ & \\
\hline 10 & 4,9914 & 0 & $N T$ & \\
\hline 11 & 5,076 & 0 & $N T$ & \\
\hline Control - & \multicolumn{2}{|c|}{ Sin extracto } & Control & - \\
\hline Control + & Caldo Müeller Hinton & Control + & + \\
\hline
\end{tabular}

Fuente: Elaboración propia

En la Tabla $N^{\circ} 03$, se observa la Concentración Mínima Inhibitoria a partir del tercer tubo $(4,3992 \mathrm{mg} / \mathrm{mL})$ y la Concentración Mínima Bactericida se muestra a partir del cuarto tubo $(4,4838 \mathrm{mg} / \mathrm{mL})$ producido por la actividad antibacteriana "in vitro" del extracto hidroalcohólico de las hojas de Polylepis rugulosa ("queñua") frente a Staphylococcus aureus ATCC 25923.

Tabla $N^{o}$ 04: CMI y CMB producido por la actividad antibacteriana "in vitro" del extracto hidroalcohólico de las hojas Polylepis rugulosa ("queñua") frente a la cepa uropatógena Escherichia coli.

\begin{tabular}{|c|c|c|c|c|}
\hline $\begin{array}{c}\mathrm{N}^{\circ} \\
\text { PLACA }\end{array}$ & $\begin{array}{c}\text { Conc. } \\
\text { (mg/mL) }\end{array}$ & UFC/Placa & Turbidez & Observaciones \\
\hline 1 & 3,1725 & 5 & $\mathrm{~T}$ & \\
\hline 2 & 3,125 & 2 & NT & CMI \\
\hline 3 & 3,2994 & 1 & NT & \\
\hline 4 & 3,36285 & CMB & NT & $\mathrm{CMB}$ \\
\hline 5 & 3,4263 & 0 & NT & \\
\hline 6 & 3,48975 & 0 & NT & \\
\hline 7 & 3,5532 & 0 & NT & \\
\hline 8 & 3,61665 & 0 & NT & \\
\hline 9 & 3,6801 & 0 & NT & \\
\hline 10 & 3,74355 & 0 & NT & \\
\hline 11 & 3,807 & 0 & NT & \\
\hline \multirow[b]{2}{*}{ Control } & Control - & $\begin{array}{l}\text { SIN } \\
\text { EXTRACTO }\end{array}$ & - & Control - \\
\hline & Control + & $\begin{array}{l}\text { AGAR } \\
\text { MULLER } \\
\text { HINTON } \\
\end{array}$ & + & Control + \\
\hline
\end{tabular}

Fuente: Elaboración propia
En la Tabla N ${ }^{\circ} 04$, se observa la Concentración Mínima Inhibitoria a partir del segundo tubo $(3,23595 \mathrm{mg} / \mathrm{mL})$ y la Concentración Mínima Bactericida se muestra a partir del cuarto tubo $(3,36285 \mathrm{mg} / \mathrm{mL})$ producido por la actividad antibacteriana "in vitro" del extracto hidroalcohólico de las hojas de la"queñua" frente a la cepa uropatógena Escherichia coli.

\section{DISCUSIÓN}

Muchas veces las plantas medicinales representan el único recurso terapéutico disponible para los sectores más desfavorecidos de la población (Sharapin, 2002). Según la OMS y la FAO calculan que las dos terceras partes de la población mundial, recurren al uso de las plantas medicinales.

El propósito de este trabajo fue evaluar la actividad antibacteriana de las hojas de Polylepis rugulosa ("queñua") con el fin de validar científicamente las propiedades terapéuticas de esta planta utilizada en la medicina popular como en afecciones digestivas, respiratorias y renales.

El estudio del análisis fitoquímico revela que el extracto hidroalcohólico de las hojas de "queñua", contiene en mayor concentración flavonoides, taninos, quinonas, fenoles, seguido de las saponinas y en pequeñas cantidades de triterpenos y esteroides. Bareño y cols (2010), demostraron que la actividad antibacteriana de la especie Hesperomeles obtusifoliaera era atribuida a los metabolitos secundarios, taninos, flavonoides, triterpenos, carotenoides, esteroides, y presentaba inhibición significativa frente a la bacteria $\boldsymbol{S}$. aureus. Del mismo modo Rossi y cols (2002), utilizando el método Kirby Bauer demostraron que la actividad antimicrobiana de Lepechinia meyenii frente a Staphylococcus aureus, era debido a la presencia de flavonoides, compuestos fenólicos, triterpenos, esteroides, saponinas y taninos; presentando un halo de inhibición de $13 \mathrm{~mm}$ a una concentración de $100 \mathrm{mg} / \mathrm{mL}$.

La actividad antibacteriana observada en el presente trabajo podría ser atribuida a la interacción (Bruneton, 2001) de compuestos fenólicos y flavonoides, conocidos por tener propiedades antiinflamatorias, antibacterianas y antifungicas. (Lock de Ugaz, 1994), cuya acción es la de provocar lesiones en la membrana citoplasmática, ocasionando alteración en la composición interna de la célula bacteriana, además de la acción de los taninos y quinonas conocidos por ser inhibidores de la actividad enzimática, precipitando las proteinas (Bruneton, 2001).

Mediante el método de difusión en agar, se demostró que el extracto hidroalcohólico de las hojas de "queñua" presenta actividad antibacteriana sobre Staphylococcus aureus ATCC 25923, produciéndose un halo de $11,2 \mathrm{~mm}$ a una concentración de $4,375 \mathrm{mg} / \mathrm{mL}$ y para la cepa de Escherichia coli se obtuvo un halo de inhibición de $11,35 \mathrm{~mm}$ a una concentración de $3,125 \mathrm{mg} / \mathrm{mL}$. Se trabajó con las cepas seleccionadas por que son muy comunes en infecciones nosocomiales y 
muy dificiles de erradicar. La prueba de susceptibilidad de difusión del disco (Kirby Bauer) permitió conocer la sensibilidad bacteriana en función del halo de inhibición extracto hidroalcohólico y los antibióticos utilizados en el presente trabajo.

Los controles evidenciaron la validez de las variaciones de los promedios resultantes de la actividad antibacteriana "in vitro" sometido a los tratamientos por el extracto hidroalcohólico, el control negativo mostró crecimiento bacteriano en el cultivo de la placa control y el control positivo manifiesta la ausencia de halos de inhibición.

La actividad antibacteriana del extracto hidroalcohólico de las hojas de "queñua" sobre $\boldsymbol{S}$. aureus ATCC 25923 fue a una Concentración Mínima Inhibitoria de 4,375 $\mathrm{mg} / \mathrm{mL}$ con halo de $11,2 \mathrm{~mm}$ por el método difusión en disco (Kirby Bauer) resultados similares fueron obtenidos también por Daud y cols. (2008), quienes reportaron una actividad antibacteriana del extracto alcohólico de las hojas de Polylepis australis frente a Staphylococcus aureus formando un halo de inhibición de $9,5 \mathrm{~mm}$ de diámetro y su CMI fue de $1,25 \mathrm{mg} / \mathrm{mL}$.

La mayor actividad antibacteriana del extracto hidroalcohólico de las hojas de "queñua" fue sobre $\boldsymbol{E}$. coli, que en el presente trabajo la Concentración Mínima Inhibitoria fue de $3,125 \mathrm{mg} / \mathrm{mL}$ con un halo de inhibición de11,35 mm por el método difusión en disco (Kirby Bauer).

Otra manera de demostrar la validez de la actividad antibacteriana "in vitro" del extracto hidroalcohólico de las hojas de la "queñua" fue cuando se comparó con los antibióticos: Se encontró una similitud en el diámetro del halo de inhibición producido por la Azitromicina ( Azd) $15 \mathrm{mg} / \mathrm{mL}$ (15 mm), con el extracto de la "queñua" a una concentración de $6,25 \mathrm{mg} / \mathrm{mL}(15,45 \mathrm{~mm})$, lo que demuestra que esta concentración es similar al efecto antibacteriano "in vitro" del antibiótico frente a Staphylococcus aureus ATCC 25923.

Los resultados del presente trabajo permitieron afirmar que las hojas de la "queñua" es productora de sustancias bioactivas con efecto antibacteriano "in vitro" frente a Staphylococcus aureus ATCC 25923 y cepa uropatógena Escherichia coli.

\section{CONCLUSIONES}

- Se demostró que el extracto hidroalcohólico de las hojas de Polylepis rugulosa ("queñua"), presentó actividad antibacteriana "in vitro" frente a $S$. aureus ATCC 25923 y a la cepa E. coli. Por el método difusión del disco (Kirby-Bauer), Concentración Mínima Inhibitoria (CMI) y del extracto hidroalcohólico de las hojas de Polylepis rugulosa (queñua) frente a $\boldsymbol{S}$. aureus ATCC 25923 fue de $4,375 \mathrm{mg} / \mathrm{mL}$ y para la cepa uropatógena $\boldsymbol{E}$. coli $\mathrm{es}$ de $3,125 \mathrm{mg} / \mathrm{mL}$.
- El estudio fitoquímico de las hojas de "queñua" del extracto hidroalcohólico presentó en mayor porcentaje flavonoides, taninos, quinonas, y fenoles, seguido de saponinas y pequeñas cantidades de triterpenos y esteroides, la actividad antibacteriana podría ser atribuida a flavonoides, fenoles, , además de la acción de los taninos y quinonas.

\section{RECOMENDACIONES}

- Se recomienda realizar pruebas experimentales "in vitro" del extracto hidroalcohólico de las hojas de Polylepis rugulosa ("queñua"), frente a otros microorganismos de importancia clínica.

- Realizar otros métodos de extracción de las hojas de Polylepis rugulosa ("queñua") para las pruebas de comparación del extracto hidroalcohólico, de este modo lograr cuan efectiva son las diferentes extracciones y como variarán su actividad antibacteriana.

\section{REFERENCIAS BIBLIOGRÁFICAS}

1. Alvarado, V.; Moroni, N. (2010). "Plantas Medicinales: Efectoanti bacterianoin vitro de Plantago major L, Erythroxylum novogranatense, Plowman variedad truxillense y Camelliasinensis sobre bacterias de importancia estomatológica". Rev. Odontología Sanmarquina 13(2): 21-25. Lima - Perú.

2. Angulo, H.(1996). "La Etnofarmacología y los Medicamentos del siglo XXI". Segundo Simposium sobre plantas medicinales y medicamento vegetal en el Perú. Lima.

3. Astete M. S.; Flores F.; Buckley A.; Villarreal J. (2004). Sensibilidad antibiótica de los gérmenes causantes de infecciones urinarias en pacientes ambulatorios en el Hospital Nacional Arzobispo Loayza. Rev. Soc. Per. Med. Inter. 17(1).

4. Bareño, L.; Cortes, A.; Castrillon, W.; Plazas, E. (2010). "Estudio Fitoquímico y de Actividad Antibacterial de la especie Hesperomeles obtusifolia". XXIX Congreso Latinoamericano de Química. Universidad Distrital Francisco José de Caldas, Bogotá - Colombia.

5. Bob, Freeman; Burrows, W. (1989). "Microbiología de Burrows". $22^{\text {ava }}$. Edición, Editorial Mac Graw Hill, México.

6. Boyd M.R.(1996). "The Position of Intellectual Property Rights in Drug Discovery and Developments from Natural Products". Journal of Ethnopharmacology. 51:17-27.

7. Brenner, Don J.; Krieg, Noel R.; Staley, James T. (2005). "Bergey's Manual_ Of Systematic

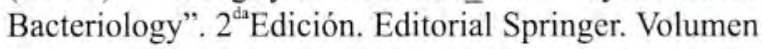
2. 
8. Bruneton, J.; Villar Del F., A.; Accame, C.(1991). "Elementos de Fitoquímica y Farmacognosia". Acribia, Zaragoza. Pp.355-358. España.

9. Bruneton, Jean. (2001). "Farmacognosia, Fitoquímica, Plantas Medicinales". Editorial Acribia. 1099 pags. Zaragoza/Es.

10. Bruneton, Jean. (2001). "Plantas Toxicas, Vegetales Peligrosos para el Hombre y los Animales". Editorial Acribia. 527 pags. Zaragoza/Es.

11. Bustos, Jaime; Hamdan, Aída; Gutiérrez, Marcia.(2006). "Staphylococcus aureus: la reemergencia de un patógeno en la comunidad". Depto. de Atención a la Salud, Depto. de Sistemas Biológicos. Universidad Autónoma Metropolitana, Xochimilco. México, D.F., México. RevBiomed; 17:287-305.

12. Caceres M. César: 2004. "Taxonomía y usos tradicionales de las plantas tradicionales de la provincia de Candarave - Tacna". Universidad Nacional Jorge Basadre Grohmann. FACI-ESMB. PERU. 124 p.

13. Carvajal, L.; Hata, Y.; Sierra, N.; Rueda, D. (2009). "Análisis Fitoquímico Preliminar de hojas, tallos y semillas de Cupatá (Strychnosschultesiana krukoff)". Revista Colombia Forestal Vol. 12: 161-170/ Diciembre - Colombia.

14. Condori, Marleni. (2008). "Efecto Antibacteriano in vitro del Extracto Metanólico de Plantago lanceolata (llantén) frente a $S$. aureus y $E$. coli". Universidad Nacional Jorge Basadre Grohmann. FACM-ESFB. Tacna-Perú.

15. Corahua V. Liz. (2009). "Caracterización molecular de las cepas de E. coli uropatógenas aisladas de pacientes mujeres con infección del tracto urinario del distrito de Comas". Universidad Nacional Mayor de San Marcos. Tesis. Lima Perú.

16. Cowan, M. M. (1999). "Plant products as antimicrobial agents". Clin Microbiol Rev.; 12:564-82.

17. Daud A.; Habib, N.; Sánchez, S.(2007). "Actividad Diurética de Extractos Acuosos de Polylepis australis Bitter ("queñoa"). Rev. Cubana Plant. Med. Vol.12 N.4 Ciudad de la Habana.

18. Daud, A.; Habib, N.; Sánchez, S.(2008). "Actividad Antimicrobiana de Extractos Alcohólicos de hojas y corteza de Polylepis australis Bitter ( "queñoa"). Rev. Cubana PlantMed. Vol.13 N 3 Ciudad de la Habana July-Sept.

19. Dawson B. Y Trapp R. (2005). "Bioestadística Medica". Editorial Manual Moderno. 392 pags. México/Mx.

20. Diaz R.; Gamazo, C.; Lopez, G.(2001). "Manual Práctico de Microbiología". Editorial Massonsa. Barcelona. $3^{\text {era }}$. Edición. p 98 .
21. Dinges, M.; Orwin, P.; Schlievert, P.( 2000). "Exotoxins of S. aureus". Clin. Microbiol. Rev. 13:1634.

22. Duerden, B.I.; Reid, T.; Jewsbury, J.; Turk, D.(1993). Microbiología: Enfermedades Infecciosas. Editorial Limusa. Mexico.337p.

23. Domingo D.; Lopez M. (2003). "Plantas con Acción Antimicrobiana".Rev. Sociedad Española de Quimioterapia, diciembre, Vol. 16 (N²4);385-393 p.

24. Fuertes, C.; Roque, M.; Tristan, M.(1997). "Flavonoides y Alcaloides de Lupinus ballianus con Actividad Antibacteriana y Antifúngica". Instituto de Microbiología UNMSM.

25. García J.a.; Picazzo J.J.( 2000). "Compendio de Microbiología Médica". Ediciones Harcourt, S.A. Madrid España 118p.

26. Guevara, Diana.(2009). "Efecto Antibacteriano In Vitro Del Extracto de Brassica napus L. (nabo) Frente a Cepas de $S$. aureus". Universidad Nacional Jorge Basadre Grohmann. FACM-ESFB. Tacna-Perú.

27. Harbone, Jeffrey. (1973). "Phytochemical Methods". Champan and Hill. USA. Pp. 6-22.

28. Harvey, A.: 2000. "Strategies for Discovering Drugs from Previously Unexplored Natural Products". Drug discovery. 5(7). Review.

29. Hernandez, L. Rodriguez, J. (199)1. Activity antibacterial and antiviral agentes from higher plants used in folkloric mediana jornal of medicinal plantas reserch.

30. Jawetz, Melnick; Adelberg. (2002). "Microbiología Médica". 17 edición, Editorial El Manual Moderno, México.

31. Koneman, Elmer; Stephen, Allen. (2004). "Diagnostico Microbiológico". $5^{\text {ta }}$ Edición, Editorial Médica Panamericana, Buenos Aires.

32. Kontiokari, T.; Sundqvist, K.A.J.; Nuutinen, M.; Pokka, T.; Koskela, M.; Uhari, M.: 2001. "Randomised trial of cran berry lingon berry juice and Lactobacillus GG drink for the prevention of urinary tract infections in women". British Medical Journal.

33. Kuklinski, CL.: 2003. "Estudio de las drogas y sustancias medicamentosas de origen natural". Farmacognosia. Ediciones Omega S.A. Barcelona.

34. Lippincott, Williams \& Wilkins. (2004). "Medical Dictionary". Edición Medi Lexicon International Ltd. Editorial Bexhill-on-Sea, Reino Unido.

35. Lock De Ugaz O. (1994). "Investigación Fitoquímica, Métodos en el Estudio de Productos Naturales". $2^{\text {da }}$ Edición. Editorial Pontificia Universidad Católica del Perú. Lima. 
36. Lozano, N.; Bonilla, P.; Arroyo, J.; Arias, G.; Córdova, A.; Baldoceda, F.(2001). "La Etnofarmacología y los Bioensayos como Nuevas Estrategias en la Investigación Fitoquímica de la Flora Medicinal Peruana". Ciencia e investigación. Rev. San Marquina, Volumen V(1). ISSN 1561-0861. Volumen V (1). ISSN 1561-0861.20-36p. Lima-Perú.

37. Mandell, G.; Douglas, D; Bennet, H.; Dolin, R.(1997)."Enfermedades Infecciosas. Principios y Practica”. $4^{\text {ta }}$ Edición. Editorial Médica Panamericana, S.A. Buenos Aires-Argentina. 243 p.

38. Margall, N.; Domínguez, A.; Prast, G.; Salleras, Ll. (1997). "E. coli Enterohemorrágica". Revista Española. Salud Pública. Volumen 71 N .5 Madrid. Sept./Oct.

39. Mensa J. (1995). "Infecciones Urinarias". En Ferreras-Rozman Medicina Interna. Editorial Doyma. España. 90p.

40. Menudo R. (1995). "Lecciones de Microbiología y Medios de Cultivo. Manual de Laboratorio". Editorial Limusa. $4^{\text {ta }}$ Edición.

41. Midzuaray, A.: 1998. "Manual de Terapia Médica". Ediciones Servicio de Medicina Pro-vida. Lima-Perú. 386.

42. Mins, C.; Playfair, J.; Roit, I.; Wakelin, D.; Wilim, R.(1995). "Microbiología Médica". Mosby/Doyma Libros División de Times Mirror de España. S.A.

43. Morales A. Luis.(2009). "Caracterización Fenotípica del Género Polylepis en el Bosque Nativo de la Provincia de Candarave-Tacna". Universidad Nacional Jorge Basadre Grohmann. Tesis. FACIESMB. Perú.

44. Murray P.; Rosentahl K.; Kobayashi S.; Pfaller G.(2002). "Microbiología Medica". 4 Edición; Editorial SevierScience.

45. Neira, A.; Ramírez, M.; Sánchez, N. (2005). "Estudio fitoquímico y actividad antibacterial de Psidium guineense Sw ("choba") frente a Streptococcus mutans, agente causal de caries dentales". Colombia.

46. Pahlow, M. (1985). "El Gran Libro de las Plantas Medicinales". Editorial Everest. España. Pp. 22-26.

47. Palacios Lozada, Enrique. (2004). "Economía y plantas medicinales”. Universidad NMSM. Boletín 52. ISSN 1727-4389. Pp 28.

48. Perea, E. (1992). Enfermedades Infecciosas y Microbiología Clínica. Editorial Doyma. España. 201205 p.

49. Prats G. Pastor. (2005). "Microbiología Clínica". $1^{\text {ra }}$ Edición, Editorial médica Panamericana, Buenos Aires. $48 \mathrm{p}$.
50. Prieto, P. Jose; Fraile De La R. Manuel. (1997). "Microbiología en Ciencias de la Salud" Conceptos y Aplicaciones. $1^{\text {era }}$ Edición. Madrid-España.

51. Rodriguez, Angeles; Guadalupe, M. (2002). "Principales características y diagnóstico de los grupos patógenos de E. coli". Salud Pública Mex 44:464-475.

52. Rodríguez,A.; Delgado, M.; Mora, R.; González, Y.; Guardia, A. (2004). "Infección hospitalaria. Resistencia bacteriana "in vitro" a los antimicrobianos usados en las instituciones de salud de ciudad de la Habana/año 2003". Rev. Panam Infectol; 6(3):8-12p.

53. Romero Cd, Chopin Sf, Buck G, Martinez E, García M, Bixby L.(2005). "Antibacterial properties of common herbal remedies of the southwest". J Ethnopharmacol. ; 99:253-7.

54. Rosalind, M.: 1985. "Infecciones Urinarias". Editorial Científica PLM, S. A. de C. V. México. 61p.

55. Rossi C.; Arias, Gl., Lozano, N.(2002). "Evaluación Antimicrobiana y Fitoquímica de Lepechinia meyeni Walp ("salvia"). Universidad Nacional Mayor de San Marcos. Lima-Perú.

56. Rotger, R. 1997, "Microbiología Sanitaria y Clínica”. Editorial Sintesis S.A. Madrid-España.625 p.

57. Sánchez, J. 2011. "Determinación de la Actividad Antibacteriana in vitro del Aceite Esencial de Allium cepa L. ("cebolla") Frente a E. coli". Universidad Nacional Jorge Basadre Grohmann. FACS-ESFB. Tacna-Perú

58. Shaechter, M.; Medoff, G.; Eisentein, B.; Guerra, H.(1994). "Microbiologia: Mecanismos de Las Enfermedades Infecciosas". Tercera edición. Editorial Médica Panamericana S.A. Buenos Aires-Argentina. 769 p.

59. Sharapin, N.(2002). "Materias primas vegetales para la industria de productos fitofarmacéuticos". Revista de Fitoterapia 1 (3): 23-28.

60. Svanborg- Eden, C.; Haglberg, L.; Hasson, A. (1990). "Adhesion of Escherichia coli in urinary tract infection”. Amj.med (1):742 p.

61. Trease, G.e.; Evans, W.C. (1993). "Tratado de Farmacognosia". 15 Ed. Editorial Blume. España. Pp. 263-280, 728-730.

62. Velázquez-meza, M. (2005). "Surgimiento y diseminación de $S$. aureus meticilinorresistente". Salud Pública-México 47:381-387p.

63. Volák, J; Stodola, J.: 1992. "Plantas medicinales". Susaeta. Checoslovaquia. Pp 6-11,33. 
64. Zeballos, H.; Ochoa J.; López, E. (2010). "Diversidad Biológica de la Reserva Nacional de Salinas y Aguada Blanca". Lima: DESCO, PROFONANPE, SERNANP. $314 \mathrm{pp}$.

\section{Informes y Revistas}

Comunidad Andina: 2007. Lineamiento Estratégico para la Conservación de Bosques de Polylepis en Colombia, taller "Esperanza para los Bosques de Polylepis" 31 mayo. Fundación PROAVES. American bird conservancy.

Instituto Nacional De Salud: 2008. "Informe de la resistencia Antimicrobiana en bacterias de origen hospitalario en Lima". Laboratorio de IRAs e IIH. CNSP. Lima-Perú.

Informe Minsa 2003 INC (2004-2006). Resistencia bacteriana en cuidados intensivos y tendencia actual: Departamento de Cuidados Críticos del Hospital Nacional Guillermo Almenara Irigoyen, Essalud, Lima, Perú.

National Nosocomial Infectious Surveillance System Nnis; 2004. "System Report", data summary from January 1992 through June 2004, issued October 2004.

Organización Mundial De La Salud; 2000 Boletín de Medicamentos Esenciales CH-1211 Ginebra 27, Suiz.

Sociedad Española de Ginecología y Obtetricia (sego) y la Asociación Española Deurología (AEU). 2007 "Infecciones urinarias". Editorial Jurado Ciudadano Zambon. 17 de mayo.
Tratado De Cooperación Amazónica. 1995. "Plantas Medicinales Amazónicas: Realidad y Perspectivas". Ediciones (TCA), Editorial Prom Amazonia. Lima-Perú

\section{Páginas Web:}

Administración de Alimentos y Medicamentos (FDA)http://www.fda.gov2008.

Programa de las Naciones Unidas para el Medio Ambiente Oficina Regional para América Latina y el $\mathrm{C}$ a $\mathrm{r}$ i b e U N E P/R O L A C 20005 http://www.pnuma.org/deramb/GroupofLikeMin dedMegadiverseCountries.php.

MedilexiconInternationalLtd http://www.medilexicon.com/medicaldictionary.p hp?t=31141.

Unión Internacional para la Conservación de la Naturaleza www.iucn.org/es/.

World Conservation Monitoring Centre 1998. Polylepis rugulosa. 2006 Lista Roja de la UICN de Especies Amenazadas. Descargado el 23 de agosto de 2007.

\section{Correspondencia:}

César Julio Cáceda Quiroz

Universidad Jorge Basadre Grohmann Av. Miraflores s/n Fundo "los Granados" julce_caceda@yahoo.es 